\title{
INDUÇÃO DA BROTAÇÃO DA MACIEIRA 'EVA' EM REGIÃO DE BAIXA INCIDÊNCIA DE FRIO'
}

\author{
SÉRGIO RUFFO ROBERTO², MARCEL HIROAKI KAGUEYAMA, CRISTIANO EZEQUIEL DOS SANTOS ${ }^{4}$
}

\begin{abstract}
RESUMO - A macieira caracteriza-se pela queda das folhas no final do ciclo e a conseqüente entrada em dormência. Na região norte do Paraná, onde o frio é insuficiente para a quebra natural da dormência da macieira, é necessário o uso de produtos químicos para estimular a brotação das plantas. O objetivo deste trabalho foi comparar o efeito de diferentes doses de cianamida hidrogenada, associada ao óleo mineral, sobre a quebra de dormência de gemas da macieira 'Eva', na região de Londrina-PR. Foi avaliado o efeito da aplicação de cinco concentrações de cianamida hidrogenada $(0,00 \% ; 0,25 \% ; 0,50 \% ; 0,75 \%$ e $1,00 \%)$, associadas ao óleo mineral 3\%, sobre a quebra de dormência das gemas laterais e terminais das plantas. Avaliou-se a relação entre o número de frutos e o número de gemas brotadas por ramo de cada tratamento. Observou-se que a cianamida hidrogenada $0,50 \%$ associada ao óleo mineral $3 \%$ foi a concentração que resultou na melhor eficiência da brotação das gemas e da frutificação da macieira 'Eva' na região.
\end{abstract}

Termos para indexação: Malus domestica, maçã, cianamida hidrogenada.

\section{SHOOTING INDUCTION OF 'EVA' APPLE UNDER LOW INCIDENCE OF COLD WINTER}

ABSTRACT - During winter season, the apple trees show no growth due the bud dormancy. In the north of Parana State, where the cold is not sufficient to provide the natural bud break of apples, it is necessary to use chemical products to induce the growth of these plants. The objective of this research was to compare different concentrations of hydrogen cyanamide, associate to mineral oil, regarding the bud break of 'Eva' apple cultivated in Londrina region. Five concentrations of hydrogen cyanamide $(0.00 \% ; 0.25 \% ; 0.50 \% ; 0.75 \%$ and $1.00 \%)$, associated to mineral oil ( $3 \%$ ) were studied. The porcentage of lateral and terminal burst bud was evaluated as well as the relation between the number of fruits and the number of burst buds per branch of each treatment. It was possible to conclude that hydrogen cianamide at $0.50 \%+$ mineral oil $3 \%$ was the best concentration to improve the efficiency of bud growing and fruit set of 'Eva' apple cultivated in Londrina region.

Index terms: Malus domestica, apple tree, hydrogen cyanamide.

A macieira caracteriza-se pela queda das folhas no final do ciclo e a conseqüente entrada em dormência. Neste período, onde as condições de clima não são favoráveis ao crescimento, a macieira ainda apresenta atividade fisiológica, embora em níveis mínimos. Durante esta fase, reações bioquímicas específicas ocorrem no interior da planta, que são essenciais para iniciar um novo ciclo de crescimento (Petri, 1986).

A dormência das gemas é governada por condições ambientais que, por sua vez, afetam o nível das substâncias reguladoras de crescimento que controlam as mudanças metabólicas da entrada e saída da dormência (Petri et al., 2002). Entre as substâncias inibidoras de crescimento, a primeira a ser citada foi o ácido abscísico (ABA), que inibe determinados tipos de RNA, impedindo a formação de proteínas necessárias ao crescimento (Saure, 1985). A concentração de ABA diminui à medida que se aproxima o fim da dormência. Auxinas e citocininas também são citadas como susbstâncias que interferem no processo de dormência. Embora pareça não haver relação direta entre as auxinas e a saída de dormência, elas são envolvidas na abertura das gemas (Petri et al., 2002).

As baixas temperaturas durante o inverno desempenham dupla função no ciclo das macieiras, a de induzir e terminar a dormência, permitindo nova brotação. Para que a macieira inicie novo ciclo vegetativo na primavera, em condições naturais, é necessário que esta seja exposta a um período onde as temperaturas sejam inferiores a $7,2^{\circ} \mathrm{C}$ durante o inverno, sendo que este período é variável em função da cultivar (Petri et al., 1996).

Durante o período de dormência, não deve haver grandes flutuações de temperatura, pois pode acarretar à planta maior necessidade de horas de frio ou induzir um período de dormência mais prolongado, com brotação e floração desuniformes e com grande parte das gemas permanecendo dormentes. Além disso, a saída de dormência está também relacionada a outros fatores, como o estado nutricional e o vigor da árvore (Petri et al., 2002).

Nas regiões produtoras de maçãs do Paraná, onde o frio é insuficiente para induzir a brotação das macieiras, é necessário o uso de produtos químicos para provocar o estímulo da brotação das gemas (IAPAR, 1988).

A cianamida hidrogenada é o único produto eficiente que se encontra registrado para a quebra de dormência da macieira. Como a ação deste produto não é sistêmica e sim localizada, é necessário que o produto aplicado atinja as gemas das plantas para que se obtenha o efeito esperado (Castro, 1998).

A cianamida hidrogenada é comercializada com o nome de Dormex ${ }^{\circledR}$, sendo uma solução aquosa estabilizada com $52 \%$ do ingrediente ativo. O produto é degradado no solo em uréia, nitrato e amônia, comportando-se como um fertilizante nitrogenado, não deixando resíduos no solo e na planta. No Brasil, as concentrações de cianamida hidrogenada na macieira variam de $0,25 \%$ a $0,80 \%$, em função da região e da cultivar (Petri \& Palladini, 1999; Petri et al., 2002). Seu efeito é melhor quando acrescido de óleo mineral, pois este atua como protetor físico da respiração, enquanto a cianamida hidrogenada age bioquimicamente, inibindo a fosforilação oxidativa.

Para o cultivo da macieira na região de Londrina-PR, onde ocorre baixa incidência de frio durante o inverno $\left(<80\right.$ horas a $\left.7,2^{\circ} \mathrm{C}\right)$, é necessária a utilização de cultivares com baixa exigência em frio. Dentre elas, destaca-se a macieira 'Eva' (IAPAR-75), obtida pelo cruzamento entre as cultivares Gala e Anna (Hauagge \& Tsuneta, 1999).

Entretanto, poucas são as informações disponíveis sobre as concentrações de cianamida hidrogenada mais efetivas para a quebra de dormência de macieiras cultivadas em regiões de baixa incidência de frio no Paraná. Assim, o presente trabalho teve por objetivo avaliar o efeito de diferentes concentrações de cianamida hidrogenada, associadas ao óleo mineral, para a quebra de dormência da macieira 'Eva' cultivada na região de Londrina-PR.

\footnotetext{
(Trabalho 083/2005). Recebido: 13/05/2005. Aceito para publicação: 08/03/20006

${ }^{2}$ Professor Adjunto, Área de Fruticultura. Pesquisador do CNPq em Produtividade em Pesquisa. Departamento de Agronomia. Universidade Estadual de Londrina, C.P. 6001, CEP 86051-990, Londrina-PR. (43) 3371 4774. e-mail: sroberto@uel.br

${ }^{3}$ Acadêmico do Curso de Agronomia, Universidade Estadual de Londrina-PR.

${ }^{4}$ Aluno regular do Curso de Pós-Graduação em Agronomia, Área de Concentração em Fitotecnia, nível de Mestrado, Universidade Estadual de Londrina-PR. Bolsista da CAPES. e-mail: cristiano_e@yahoo.com.br
} 
O ensaio foi realizado no inverno de 2004, em um pomar comercial da macieira 'Eva' (Malus domestica) enxertada no portaenxerto 'Maruba' e filtro 'M9', com três anos de idade, no espaçamento de 5,2 m x 1,70 m, situado no município de Cambé-PR (23¹4’282" S, 51 ${ }^{\circ} 13^{\prime} 319^{\prime \prime} \mathrm{W}$ e $553 \mathrm{~m}$ de altitude). O clima, segundo a classificação do Köppen, é do tipo Cfa, ou seja, clima subtropical úmido, com chuvas em todas as estações, com baixas precipitações no período de inverno.

Os tratamentos consistiram na aplicação de cianamida hidrogenada $(\mathrm{CH})$ em diferentes concentrações associadas ao óleo mineral 3\% (Assist $\left.{ }^{\circledR}\right)$, exceto para a testemunha, que não recebeu aplicação alguma. Os tratamentos empregados foram:
a. Testemunha - sem aplicação;
b. $\mathrm{CH}-0,25 \%$;
c. $\mathrm{CH}-0,50 \%$;
d. $\mathrm{CH}-0,75 \%$;
e. $\mathrm{CH}-1,00 \%$.

A aplicação dos tratamentos foi realizada no estágio fenológico $\mathrm{C}$, isto é, quando as gemas se encontravam com pontas verdes, no dia 29 de julho de 2004. Para a aplicação dos tratamentos, utilizou-se de um pulverizador costal de 20 litros, com bico cone, pulverizando-se todos os ramos da planta até o ponto de escorrimento.

O delineamento estatístico foi o inteiramente casualizado, com 5 tratamentos e 5 repetições, sendo cada parcela composta por uma planta. Foram marcados 10 ramos por parcela para as avaliações.

Após 50 dias da aplicação dos tratamentos, foram avaliadas a porcentagem de gemas laterais e terminais brotadas dos ramos marcados (Petri, 1997; Cruz Júnior \& Ayub, 2002). Uma vez que os ramos marcados por parcela possuíam número variável de gemas, após a frutificação efetiva e raleio de frutos, avaliou-se a relação entre o número de frutos e o número de gemas brotadas por ramo de cada tratamento, expressa em porcentagem, para se determinar a eficiência dos tratamentos sobre a produção de frutos.

A eficiência das diferentes concentrações de cianamida hidrogenada sobre as variáveis analisadas foi determinada através da análise de regressão dos dados no aplicativo Statistica ${ }^{\circledR}$.

Em relação à porcentagem de gemas laterais brotadas, verificouse que os tratamentos com $0,50 \%, 0,75 \%$ e $1,00 \%$ de $\mathrm{CH}$ mostraram melhores respostas quanto à quebra de dormência em relação aos demais tratamentos (Figura 1), muito embora tenha-se observado no máximo $48,8 \%$ de gemas brotadas aos 50 dias após a aplicação, ou seja, na medida em que a concentração de $\mathrm{CH}$ aumentou, observou-se incremento da brotação de gemas laterais da macieira. Entretanto, observou-se que os tratamentos onde se empregaram as maiores concentrações de $\mathrm{CH}(0,50 \%, 0,75 \%$ e $1,00 \%)$, resultaram em maior eficiência na quebra de dormência das gemas laterais em relação à testemunha e à $\mathrm{CH} 0,25 \%$. Embora a temperatura pós-aplicação dos tratamentos tenha sido suficiente para que ocorresse a brotação das gemas, o período de estiagem prolongado observado no período (50 dias) pode ter reduzido o potencial dos tratamentos em induzir a brotação das gemas.

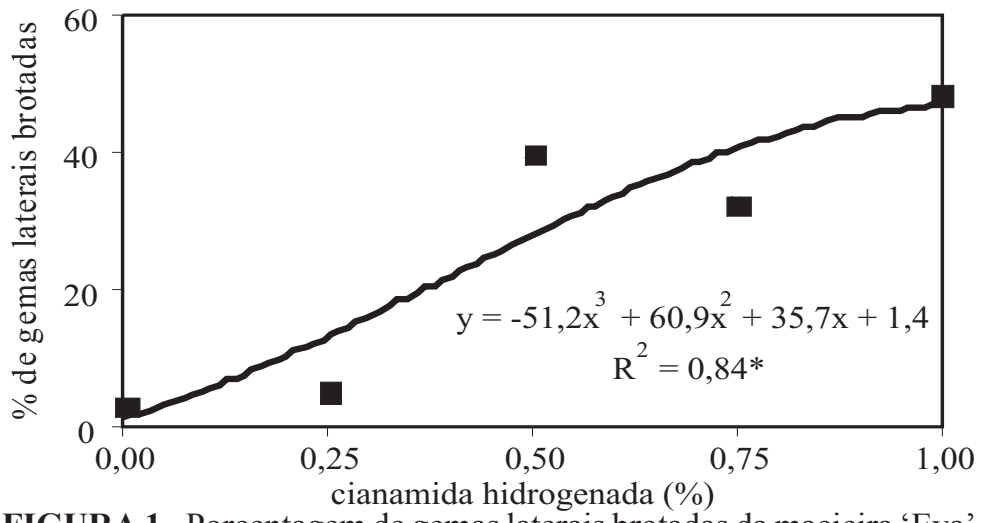

FIGURA 1 - Porcentagem de gemas laterais brotadas da macieira 'Eva' (Malus domestica) em função de diferentes concentrações de cianamida hidrogenada. Obs: * significativo $(P<0,05)$.
$\mathrm{O}$ tratamento $\mathrm{CH} \quad 0,25 \%$ apresentou eficiência similar à testemunha, o que indica que a aplicação da $\mathrm{CH}$ nesta concentração não resulta em incremento na brotação de gemas da macieira 'Eva'. Por outro lado, verifica-se que concentrações superiores de $\mathrm{CH}(0,50 \%$; $0,75 \%$ e $1,00 \%$ ), resultam em incremento na brotação de gemas; porém, até um determinado patamar, ou seja, concentrações de $\mathrm{CH}$ acima de $0,50 \%$ não resultam em incremento na brotação de gemas laterais brotadas da macieira 'Eva', na região de Londrina. Resultados semelhantes foram observados por Iuchi et al. (2002), os quais verificaram na região de São Joaquim-SC, que, embora doses crescentes de cianamida hidrogenada apresentem efeito linear na brotação das gemas laterais da macieira 'Fuji', doses acima de $0,50 \%$ não resultam em incremento da brotação das gemas.

Quanto à porcentagem de gemas terminais brotadas, verificouse que os tratamentos com $0,50 \%, 0,75 \%$ e $1,00 \%$ de $\mathrm{CH}$ mostraram melhores respostas em relação aos demais tratamentos (Figura 2). Observou-se que os tratamentos onde se empregaram as maiores concentrações de $\mathrm{CH}(0,50 \%, 0,75 \%$ e $1,00 \%)$ apresentaram maior eficiência em relação à testemunha e à $\mathrm{CH} 0,25 \%$.

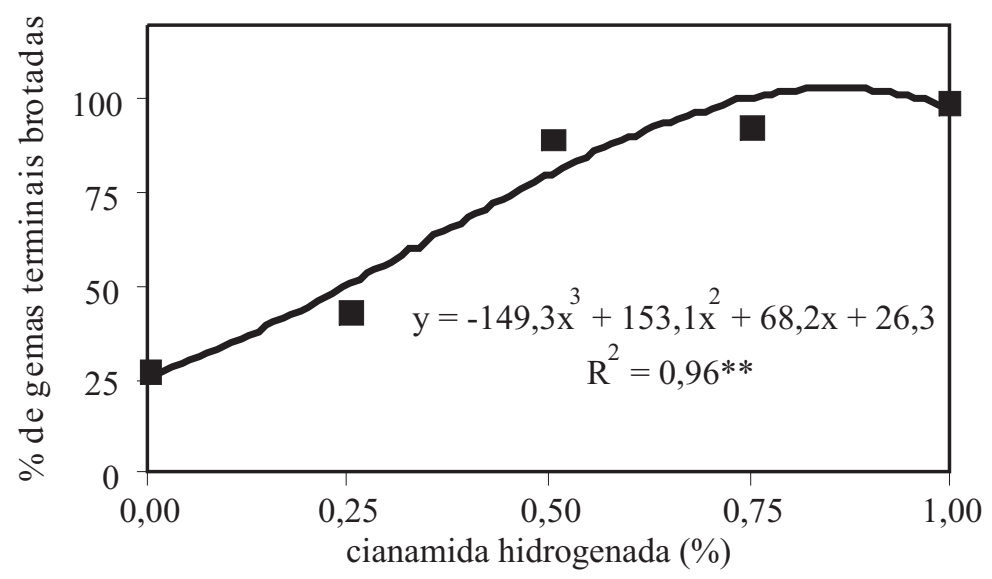

FIGURA 2 - Porcentagem de gemas terminais brotadas da macieira 'Eva' (Malus domestica) submetida a diferentes concentrações de cianamida hidrogenada. Obs: ** significativo $(P<0,01)$.

Esses resultados indicam que concentrações mais elevadas de $\mathrm{CH}$ exercem influência sobre a brotação de gemas terminais até um determinado patamar, ou seja, concentrações de $\mathrm{CH}$ acima de $0,50 \%$ não resultam em incremento da brotação de gemas terminais da macieira 'Eva', conforme observado para a brotação de gemas laterais.

Comparando os dados da Figura 1 com a Figura 2, observouse que a porcentagem de gemas terminais brotadas foi maior em relação às gemas laterais. Isso se deve ao fato de que as gemas laterais são mais exigentes em quantidade acumulada de frio durante o inverno, apresentando maior dificuldade para a saída de dormência (Cruz Júnior \& Ayub, 2002; Petri et al., 2002)

Verifica-se que, para as condições da região de Londrina, as doses de $\mathrm{CH}$ para induzir uma eficiente brotação de macieiras são superiores às observadas em regiões onde ocorre maior acúmulo no número de horas de frio. Na região de São Joaquim, onde a altitude varia entre 900 e $1.500 \mathrm{~m}$, Petri et al. (1996) e Iuchi et al. (2002) citam que, dependendo das condições de frio, as doses de $\mathrm{CH}$ associadas ao óleo mineral variam entre 0,15 e $0,50 \%$.

Estes resultados são semelhantes aos obtidos por Cruz Júnior \& Ayub (2002), os quais determinaram que a CH na concentração de $0,75 \%$ apresenta melhor eficiência para a quebra de dormência da macieira 'Eva' na região de Ponta Grossa-PR. Entretanto, deve-se ressaltar que, embora a região de Ponta Grossa (980 m de altitude) apresente temperaturas médias mais baixas e maior número de horas de frio que a região de Londrina (553 m de altitude), o inverno de 2004 foi mais constante e prolongado que os anos anteriores, o que contribuiu para uma melhor eficiência da quebra de dormência. Assim, em anos onde o inverno é menos constante e mais curto, espera-se melhor eficiência da 
$\mathrm{CH}$ sobre a quebra de dormência de gemas em concentrações superiores. Para a relação entre o número de frutos e o número de gemas brotadas por ramo, observou-se que os tratamentos onde se empregaram as maiores concentrações de $\mathrm{CH}(0,50 \%, 0,75 \%$ e $1,00 \%)$, apresentaram melhores respostas em relação à testemunha e à $\mathrm{CH} 0,25 \%$, resultando em maior eficiência da frutificação da macieira 'Eva' (Figura 3). A menor frutificação observada nas plantas-testemunha pode ser explicada pela menor porcentagem de gemas laterais e terminais observadas neste tratamento (Figuras 1 e 2), onde as condições naturais de frio não foram suficientes para promover uma brotação adequada das mesmas.

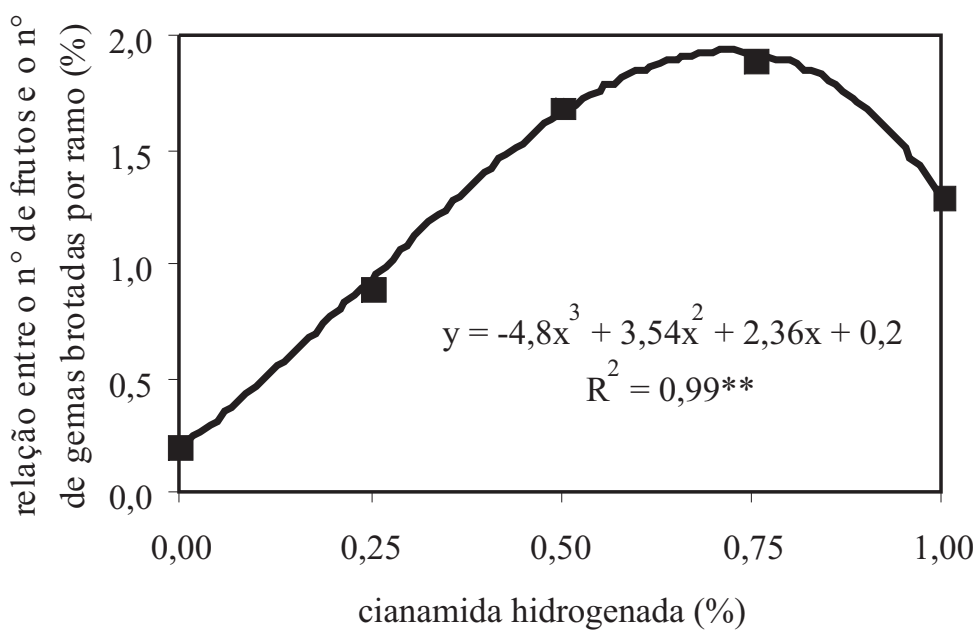

FIGURA 3 - Porcentagem do número de frutos em relação ao número de gemas brotadas por ramo da macieira 'Eva' (Malus domestica) submetida a diferentes concentrações de cianamida hidrogenada. Obs: ** significativo $(P<0,01)$.

Como foi observado comportamento semelhante entre as maiores concentrações empregadas de $\mathrm{CH}(0,50 \%, 0,75 \%$ e $1,00 \%)$, considera-se que $\mathrm{CH}$ na concentração de $0,50 \%$ é suficiente para promover melhor frutificação da macieira 'Eva'. Por fim, ressalta-se que, como o hábito de frutificação da macieira ocorre em estruturas especializadas (esporões), que levam de 2 a 4 anos para formar gemas floríferas (Petri et al., 2002), a maior eficiência de brotação de gemas, após o período de dormência, resultará em melhor formação de novos ramos com gemas diferenciadas e, conseqüentemente, maior produção de frutos na planta.

\section{REFERÊNCIAS}

CASTRO, P.R.C. Utilização de reguladores vegetais na fruticultura, na olericultura e em plantas ornamentais. Piracicaba: ESALQ, 1998. 92p.

CRUZ JÚNIOR, A.O.; AYUB, R. A. Quebra de dormência de gemas de macieira cv. Eva tratadas com cianamida hidrogenada. Revista Brasileira de Fruticultura, Jaboticabal, v.24, n.2, p.576-578, 2002.

HAUAGGE, R.; TSUNETA, M. IAPAR 75 - 'Eva', IAPAR 76 - 'Anabela' e IAPAR 77 - 'Carícia' - Novas cultivares de macieira com baixa necessidade em frio. Revista Brasileira de Fruticultura, Jaboticabal, v.21, n.3, p.239-242, 1999.

IAPAR. A cultura da macieira no Paraná. Londrina, 1988. 112p.

IUCHI, V.L.; IUCHI, T.; BRIGHENTI, E.; DITRICH, R. Quebra da dormência da macieira (Malus domestica Borkh) em São JoaquimSC. Revista Brasileira de Fruticultura, Jaboticabal, v.24, n.1, Jaboticabal, p.168-174, 2002.

PETRI, J. L. Indução de brotação de gemas de macieira por cianamida hidrogenada e óleo mineral sob influência da temperatura. Pesquisa Agropecuária Brasileira, Brasília, v.32, n.1, p.71-75, 1997.

PETRI, J.L. Dormência da macieira. In: PARRA, J.R.P. et al. Manual da cultura da macieira. Florianópolis: EMPASC, 1986. p.163-187.

PETRI, J.L.; PALLADINI, J.A.; POLA., A.C. Dormência e indução da brotação da macieira. In: EPAGRI. A cultura da macieira. Florianópolis, 2002.p.261-298.

PETRI, J.L.; PALLADINI, L.A. Eficiência de diferentes volumes e concentrações de calda para a quebra de dormência na macieira cultivar Gala. Pesquisa Agropecuária Brasileira, Brasília, v.34, n.8, p.1491-1495, 1999.

PETRI, J.L.; PALLADINI, L.A.; SHUCK, E.; DUCROQUET, J.H.H.J.; MATOS, C.S. Dormência e indução da brotação de fruteiras de clima temperado. Florianópolis: Epagri, 1996.110p.

SAURE, M.C. Dormancy release in deciduous fruit trees. Horticultural Reviews, Westport, v.7, p.239-299, 1985. 